\title{
Recharge of natural mineral water Jingyu County, northeastern China
}

\author{
Xiujuan Liang, ${ }^{1,}$, Hui Tian ${ }^{1}$, Changlai Xiao ${ }^{1}$, Mingqian $\mathrm{Li}^{1}$, Ying $\mathrm{Sun}^{1}$, and Yinxi $\mathrm{Li}^{2}$ \\ ${ }^{1}$ Key Laboratory of Groundwater Resources and Environment, Ministry of Education, Jilin \\ University, No 2519, Jiefang Road, Changchun130021, PR China; \\ ${ }^{2}$ Changbai Mountain Natural Mineral Water Research Center, Baishan, Jilin, 135200, PR China
}

\begin{abstract}
A light stable isotope investigation of the source of natural mineral water in Jingyu County indicates an origin predominantly from atmospheric precipitation. As water-rock interaction occurs in the runoff process, $\mathrm{SiO}_{2}$ in the basaltic aquifer is dissolved, forming a metasilicate-type mineral water. The average residence time of natural mineral water in the stratum is 20 to 56 years.
\end{abstract}

\section{Introduction}

The Changbai Mountain basalt area is located in southeastern Jilin province, China and contains a remarkable mineral water center that is reputed to be one of the three largest high-quality natural mineral water sources globally [1]. The water here is metasilicate mineral water of high quality with abundant and consistent discharge which has great potential for development and economic benefit [2-4]. The fractional effect of environmental isotope in the hydrological cycle makes different water bodies with different isotope values [5-6]. Therefore, the source and age of natural mineral water can be determined using the difference between isotope composition, which is of great significance for the sustainable development and utilization of natural mineral water.

\section{Study Area}

Jingyu County is in southeastern Jilin Province, on the western periphery of the Changbai Mountains and lies along the upper reaches of the Songhua River. Jingyu County has a humid frigid-temperate climate of the northeast mountains in the East Asian Monsoon zone. The precipitation in Jingyu County is distributed unevenly. Average annual precipitation is $795 \mathrm{~mm}$, and ra8infall concentrated from June to September accounts for 59\% of average annual precipitation. The groundwater aquifers of the study area are fissures and cavities within a basalt plateau formed through multi-stage volcanic eruptions. These produce numerous large mineral water springs like Shenhua Spring, Linhai Spring, Julong Spring and many others.

\footnotetext{
* Corresponding author: lax64@126.com
} 


\section{Source determination of mineral water recharge}

As shown in Figure 1, samples analyzed in this study, all collected in the field during the low-flow season in May 2011 and the high-flow season in September 2011, are from 10 natural mineral water springs plus an experimental well sampled at three different depths.

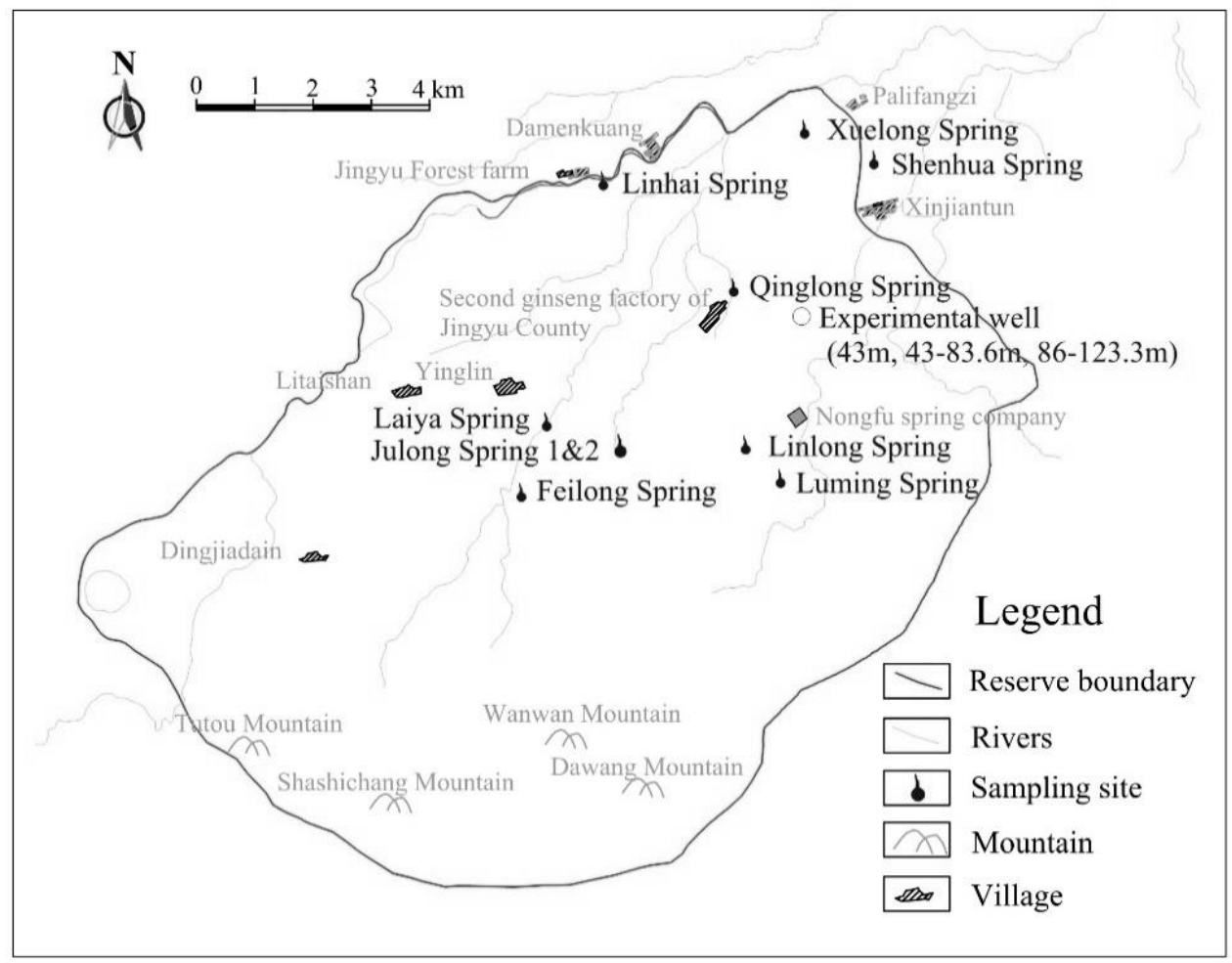

Fig. 1. Map of the study area showing the location of the surface drainage and the locations of water samples.

\subsection{Analytical Methodology}

Water samples were measured in Key Laboratory of Groundwater Resources and Environment, Ministry of Education, of Jilin University. The hydrogen and oxygen isotope $\left(\delta \mathrm{D}\right.$ and $\delta^{18} \mathrm{O}$ ) compositions analytical apparatus is Delta $\mathrm{S}$ Thermoqest gas source stable isotope mass spectrograph, and the determination of tritium using the ultra-low level liquid scintillation spectrometer.

\subsection{Hydrogen and oxygen isotope results}

The H- and O-isotopic compositions of the spring and well waters samples are shown in the Table 1, and plotted in Figure 2 on a conventional $\delta \mathrm{D}$ versus $\delta^{18} \mathrm{O}$ diagram. These waters define a linear array defined by the relationship $\delta \mathrm{D}=7.14 \delta^{18} \mathrm{O}+34.57 \%$ that lies adjacent to the LMWL, indicating an origin from atmospheric precipitation [7].

The average $\delta \mathrm{D}$ and $\delta^{18} \mathrm{O}$ values determined for Jingyu County mineral waters are -86.5 $\%$ and $-12.2 \%$ respectively and the average $\delta \mathrm{D}$ and $\delta^{18} \mathrm{O}$ values of precipitation is $-69.8 \%$ 
and $-12.4 \%$. As shown in Figure 2, $\delta \mathrm{D}$ and $\delta^{18} \mathrm{O}$ values deviate from the LMWL due to the difference of local meteorological conditions and elevation effects.

Table 1. Isotope determination and average residence times of water samples in Jingyu.

\begin{tabular}{|c|c|c|c|c|}
\hline \multirow{2}{*}{ Sampling site } & \multicolumn{3}{|c|}{ Test items } & $\begin{array}{c}\text { Groundwater Age } \\
\text { (years B.P.) }\end{array}$ \\
\cline { 2 - 5 } & $\boldsymbol{\delta}^{\mathbf{1 8}} \mathbf{O}$ (VSMOW) & $\boldsymbol{\delta D}$ (VSMOW) & Tritium (TU) & 21.04 \\
\hline Shenhua Spring & -12.01 & -85.06 & $14.24 \pm 4.27$ & 20.40 \\
\hline Linhai Spring & -12.20 & -86.52 & $14.75 \pm 4.27$ & 23.93 \\
\hline Julong1 Spring & -12.38 & -86.42 & $12.12 \pm 4.24$ & 37.00 \\
\hline Yinlong Spring & -12.25 & -87.13 & $5.85 \pm 4.21$ & 56.25 \\
\hline Luming Spring & -12.23 & -86.58 & $\leq 3$ & 26.18 \\
\hline Xuelong Spring & -12.42 & -87.30 & $10.69 \pm 4.16$ & 20.40 \\
\hline Qinglong Spring & -12.36 & -86.91 & $14.75 \pm 4.13$ & 24.59 \\
\hline Julong2 Spring & -12.38 & -87.12 & $11.68 \pm 4.20$ & 36.16 \\
\hline Laiya Spring & -12.17 & -87.19 & $6.13 \pm 4.11$ & 32.25 \\
\hline Feilong Spring & -12.38 & -87.52 & $7.62 \pm 4.11$ & 56.25 \\
\hline Well (43m) & -11.93 & -85.41 & $\leq 3$ & 32.93 \\
\hline Well (43-83.6m) & -11.98 & -85.35 & $7.34 \pm 4.18$ & 26.37 \\
\hline Well (86-123.3m) & -12.07 & -85.60 & $10.58 \pm 4.13$ & - \\
\hline Precipitation & -12.39 & -69.84 & - & \\
\hline
\end{tabular}

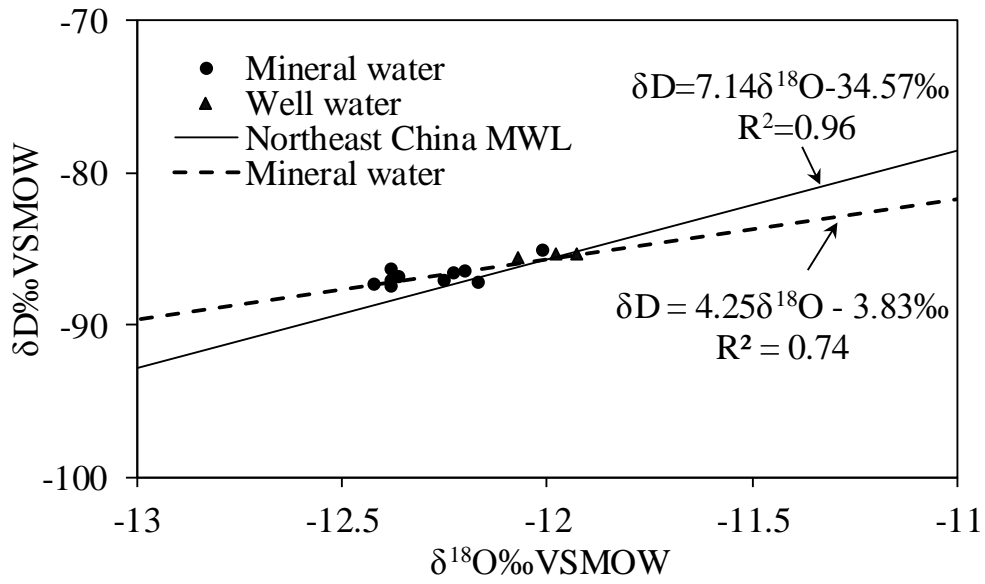

Fig. 2. Plot of $\delta \mathrm{D}$ versus $\delta^{18} \mathrm{O}$ for mineral waters of Jingyu County. This dataset defines a linear array described by the relationship $\delta \mathrm{D}=7.14 \delta^{18} \mathrm{O}+34.6$ (solid line), which for Jingyu County waters is similar to the Local Meteoric Line for northeastern China (dashed line).

The change of isotopic composition along the direction of groundwater flow is relatively small, indicating a single source of groundwater recharge, mainly by local atmospheric precipitation. The $\delta^{18} \mathrm{O}$ values indicate an accumulative tendency from the recharge area to the discharge are a(as the average values of $\delta^{18} \mathrm{O}$ in the recharge area is -12.3 while in discharge area is -12.1). The natural mineral waters discharging at the large springs of Jingyu County are concentrated in basalt fissure pore space. As these fissure pores expand into fractures, a hydrologic network is formed, providing for good connectivity for runoff 
from the recharge area to the discharge area. Also, faults and highly developed joint zones are formed in the basalt host rock as a consequence of volcanic and tectonic activities. The mineral water flows along the direction of structural expansion of the basalt plateau and appears as springs at low-lying areas, tectonic fractures, and the junction of terrains.

The isotope data of the experimental well reveal that the mineral water $\delta \mathrm{D}$ and $\delta^{18} \mathrm{O}$ values are stratified vertically, albeit the difference in the numerical values is small. As shown in Table 1, with $\delta^{18} \mathrm{O}$ and $\delta \mathrm{D}$ values decreasing slightly with depth. This observation suggests leakage from a lower aquifer, slightly depleted in $\mathrm{D}$ and ${ }^{18} \mathrm{O}$, into the upper aquifer that is the source of the mineral water springs.

\subsection{Mineral water age}

Groundwater with a tritium value of less than $1 \mathrm{TU}$ (one out of every $10^{18} \mathrm{H}$ is ${ }^{3} \mathrm{H}$ ) is formed before 1960; with a tritium value of 1 5 TU is pre-1960 that has incorporated a small amount of groundwater formed after 1960; with a tritium values between 5 30 TU are a mixtures of water both formed before and after 1960, and waters with a tritium value $>30$ TU formed entirely after 1960 [7]. Thus, the Luming spring, with a tritium value of $<3 \mathrm{TU}$, is observed to be paleo-water. The other springs that have tritium values between 5 to $15 \mathrm{TU}$, indicate the mixing of modern water and water recharged into the subsurface before 1980 .

The calculation of groundwater age by changes in radioisotopes in groundwater is mainly based on the law of radioactive decay, and the time of decay according to the relationship:

$$
t=T / 0.693 \ln \left(N_{0} / N\right)
$$

where $N$ is the measured concentration of the radioactive isotope at time $t ; N_{0}$ is the initial concentration (at $t=0$ ). The age of groundwater is measured by isotope tritium $\left({ }^{3} \mathrm{H}\right)$. By substitution of the tritium half-life $(\mathrm{T}=12.43 \mathrm{a})$ into Equation (1), the relationship of tritium concentration $(\mathrm{N})$ in groundwater and the groundwater age, i.e. average groundwater residence time, $(\mathrm{t})$ is obtained:

$$
t=17.94 \ln \left(N_{0} / N\right)
$$

Tritium values of the groundwater in the Jingyu basalt platform region fall in a very narrow range between 45 to $47 \mathrm{TU}$. Thus, taking $46 \mathrm{TU}$ taken as the initial concentration of tritium in groundwater $\left(\mathrm{N}_{0}\right)$ for the Jingyu region, it is calculated from Equation (2) that the age natural mineral waters of the study area is between 20 to 40 years (Table1), with the average residence time of groundwater in Luming Spring and the experimental well at depth $43 \mathrm{~m}$ more than 50 years.

The source of natural mineral water in Jingyu Nature Reserve is mainly from atmospheric precipitation and its vertical infiltration, and maybe a small portion from leakage of surface water. After receiving the recharge, the basalt area first becomes the reservoir of the aquifer. As the water level changes, the underground runoff also increases. Since tritium isotope in mineral water is generally 5 to 15 (TU), it can be estimated that the circulation time of groundwater in the rock should be 20 to56 years, which indicates the interval of time for water-rock reaction and the formation of mineral water as recharge travels from source area to spring discharge.

\section{Conclusions}

Based on the study of the topography, hydrogeological conditions and isotopes of the study area, the following conclusions are obtained: 
(1) According to the results of our $\mathrm{H}$ - and O-isotope study of mineral water at spring in in Jingyu County, the source of mineral water recharge is predominantly atmospheric precipitation.

(2) The average residence time of Jingyu natural mineral water in the subsurface is between 20.4 to 56.3 years, which varies for different springs. The subsurface transit time of Linhai Spring and Qinglong Spring is the shortest, about 20 years, while Luming Spring experienced the longest transit time of $\sim 50-60$ years.

Acknowledgements. This work is supported by the National Natural Science Foundation of China (41572216), Special - Leading Technology Guide (SXGJQY2017-6) of the Provincial School Co-construction Project, Shenyang Geological Survey Center project (121201007000150012) of China Geological Survey, and the Jilin Province Key Geological Foundation Projects (2014-13, 2018-11, 2018-13).

\section{References}

1. B.Z. Yan, et al., Env Geochem Health, 38, 291-307 (2016)

2. I.L. Bulia, J. Enzweiler, J Geochem Expl, 188, 43-54 (2018)

3. A.K. Provasnek, et al., J Bus Ethics, 150, 467-484 (2018)

4. Z. Dimitrios, et al., WSEAS Trans Env Dev, 75, 14-16 (2007)

5. S. Arnorsson, et al., J Geochem Expl, 69, 459-463 (2000)

6. M.J. Wirmvem, et al., Appl Water Sci, 7, 489-502 (2017)

7. J. Thomas, and T. Rose, Env Geol, 43, 532-532 (2003) 